\title{
Discurso de ódio nas redes sociais digitais: tipos e formas de intolerância na página oficial de Jair Bolsonaro no Facebook
}

\author{
Luiz Rogério Lopes Silva'
}

https://orcid.org/0000-0002-7457-9778

\section{Rodrigo Eduardo Botelho Francisco'}

https://orcid.org/0000-0002-4772-9398

\section{Rafael Cardoso Sampaio' \\ https://orcid.org/0000-0001-5176-173X \\ I - Universidade Federal do Paraná. \\ Curitiba (PR). Brasil.}

Resumo: Este artigo analisa os tipos e formas de discurso de ódio presentes na fanpage do político Jair Bolsonaro, entre os anos de 2013 e 2016 — período em que o parlamentar manifestava interesse em concorrer à presidência em 2018. Os procedimentos metodológicos envolvem uma articulação entre Mineração de Dados, Estatística e Análise do Conteúdo (AC) de 3.819.909 comentários. A extração dos dados foi realizada pelo Netvizz e um software foi desenvolvido exclusivamente para a mineração textual. A AC verificou os tipos de discursos de ódio presentes na página e a forma como os interagentes manifestaram a intolerância. Os resultados mostraram o ódio político-partidário como o mais recorrente, seguido pelo discurso sexista, LGBTfóbico e xenofóbico. As formas de manifestação mais recorrentes foram insultos e xingamentos, estereótipos e generalizações, sentimento de superioridade e ameaças. 
Palavras-chave: discurso de ódio; Jair Bolsonaro; redes sociais digitais; Facebook.

\begin{abstract}
Hate speech in digital social networks: types and forms of intolerance on Jair Bolsonaro's Facebook page - This paper aims to present a description of the hate speech on Jair Bolsonaro's fanpage between 2013 and 2016 - period when the parliamentarian manifested interest in running for president in the 2018 election. The methodological procedures required articulation of data mining methods and techniques, statistics and Content Analysis (CA) of 3,819,909 comments. Data extraction was performed by Netvizz and a software was developed exclusively for the textual mining of this research. The CA verified the sorts of hate speech on the webpage and the way interactants expressed intolerance. The results showed a significant increase in hatred between the years observed, with emphasis on political orientation, gender, LGBTphobic and xenophobic hatred. The most recurrent manifestation forms were insults and curses, accusations, stereotyping and generalizations, feelings of superiority and threats.
\end{abstract}

Keywords: hate speech; Jair Bolsonaro; digital social networks; Facebook.

\title{
Introdução
}

Este trabalho aborda o discurso de ódio em redes sociais digitais (RDS). Tal fenômeno traz consigo vários dos desafios que o campo científico da Informação e Comunicação enfrenta na atualidade, já que a Internet se tornou um terreno complexo de representações, fluxos informacionais e estabelecimento de comunicação. Trata-se de uma pesquisa exploratória, quantitativa, que tem como objetivo verificar os tipos de discursos de ódio presentes no Facebook e a forma como os interagentes manifestam a discriminação.

O conceito de discurso de ódio eleito para esta pesquisa reside no intervalo complexo entre os limites de liberdade de expressão, dignidade da pessoa e tolerância. É definido por alguns autores (BRUGGER, 2007; BROWN, 2017) como uma atitude de ódio sistemático e de agressividade irracional com relação à maneira de ser, ao estilo de vida, às crenças e às convicções de um indivíduo ou grupo de indivíduos. É manifestado por meio da discriminação de caráter religioso, nacional, racial, sexual, ético e de classe, reconhecido em discursos nazistas, racistas, xenofóbicos, homofóbicos e misóginos. Além disso, tem como elemento nuclear, para a sua identificação, a concepção de incitação à discriminação (BRUGGER, 2007). O termo é originado do inglês hate speech e, de acordo com Brugger (2007, p. 118), refere-se a "palavras 
que tendem a insultar, intimidar ou assediar pessoas em virtude de sua raça, cor, etnicidade, nacionalidade, sexo ou religião, ou que têm a capacidade de instigar violência, ódio ou discriminação contra tais pessoas".

Um campo emergente de estudos tem abordado as características do discurso de ódio em ambientes digitais, incluindo a sua manifestação nas chamadas plataformas de mídias sociais. Parte desses estudos observam em que medida as redes sociais digitais como Facebook, Twitter e Youtube deram poder a grupos racistas e supremacistas organizados, permitindo-lhes trocar know-how, desenvolver um vocabulário comum, integrar suas ideias, construir e mobilizar apoio (FROIO; GANES, 2019).

Nesse mesmo sentido, pesquisas têm questionado de que maneira as plataformas, por meio de suas affordances - gama de funções e restrições que um objeto fornece para, e coloca sobre, sujeitos estruturalmente situados -, colaboram para produção, manutenção e escalonamento da narrativa de ódio online, estimulando ou moldando o comportamento dos interagentes e a dinâmica social que se estabelece nas discussões (BEN-DAVID; FERNANDEZ, 2016; DAVIS, 2020; MENDONÇA, AMARAL, 2016).

Outros pesquisadores têm refletido sobre as causas e consequências de ações e discursos movidos pelo ódio, na tentativa de interpretar a dinâmica do fenômeno e sua estrutura linguística, abordando o que foi escrito, a forma como foi escrito, o contexto, o agressor e a vítima (BROWN, 2017; 2018). Pesquisas brasileiras anteriores foram capazes de evidenciar a presença de discurso de ódio no Facebook (MENDONÇA, AMARAL, 2016), inclusive na página oficial do Senado Federal (RIZZOTTO, SARAIVA, 2020).

No caso desta pesquisa, o interesse está no tipo e na forma do discurso de ódio manifestado em canais digitais administrados por figuras políticas. $\mathrm{O}$ estudo leva em consideração que o assédio nas redes sociais digitais, em muitos casos, aparece como comunicação estratégica, na qual mensagens específicas são criadas por atores políticos para manipular a opinião pública (MEZA et al., 2018) e "degradar simbolicamente grupos historicamente oprimidos ou sistematicamente discriminados" (SPONHOLZ, 2020, p. 221).

O objeto de estudo dessa pesquisa é a página oficial de Jair Bolsonaro à época de seu sexto e sétimo mandato como deputado federal, entre os anos de 2013 e 2016. Por sua vez, as unidades de análise são os comentários externalizados pelos seguidores desta página. Nesse contexto, uma abordagem 
multimetodológica que une Extração de Dados, Mineração de Texto e Análise de Conteúdo pretende identificar e analisar os atributos linguísticos com intenção de atingir, ofender ou diminuir grupos de características protegidas que historicamente enfrentam discriminação na sociedade.

Vale ressaltar que, para identificar os "tipos" de discurso de ódio mais recorrentes, foram analisados todos os comentários extraídos ao longo dos anos observados por meio de uma codificação automatizada. Já para análise das "formas" de discurso de ódio, foi determinada uma amostra dos comentários para codificação manual. Também foram analisadas as cinco postagens com mais engajamento a fim de encontrar algum vestígio de incitação ao ódio ou de discurso de ódio propriamente.

\section{As características do discurso de ódio}

O discurso de ódio online, também conhecido como cyberhate, pode ser reproduzido em diferentes formatos, em diferentes plataformas, e pode ser visualizado em vários contextos (MENDONÇA, AMARAL, 2016; RIZZOTTO, SARAIVA, 2020; SARMENTO, 2013; SILVA, SAMPAIO, 2017; SPONHOLZ, 2020). Entre as características que diferem o cyberhate dos modos convencionais de discurso de ódio estão:

- anonimato: as pessoas na Internet estariam mais confortáveis e encorajadas a serem mais ultrajantes, desagradáveis ou odiosas no que dizem do que estariam na vida real (CITRON, 2014; BROWN, 2018);

- alcance, permanência e itinerância do fenômeno: o cyberhate pode ser visualizado e reproduzido por uma grande audiência, permanecendo por tempo indeterminado e, mesmo quando removido, é possível que ressurja em outro lugar (GAGLIARDONE et al., 2015);

- invisibilidade: por conta da distância física entre odiador e público, é provável que a pessoa que manifesta o discurso de ódio online subestime seu significado e o dano que possa provocar ao destinatário. Essa distância gera uma invisibilidade do odiador para o público e vice-versa (BROWN, 2018);

- comunidade: a Internet permite que qualquer pessoa se envolva em discursos de ódio e atraia um público online (BROWN, 2018). Esse senso de comunidade aproxima pessoas com ideias semelhantes, incluindo pensamentos intolerantes; 
- instantaneidade: a Internet permite que a manifestação odienta alcance em questão de segundos um número grande de pessoas, o que incentiva formas de discurso de ódio por meio de reações instintivas, julgamentos não considerados, comentários improvisados, comentários não filtrados e primeiros pensamentos (CITRON, 2014; BROWN, 2018).

O cyberhate visa atingir indivíduos ou grupo de indivíduos com características protegidas por conta de estados afetivos, atributos biológicos, afiliações, condutas ou disposição (BROWN, 2017). Os discursos odientos que envolvem estados afetivos ou seus padrões têm como alvo lésbicas, gays, bissexuais, travestis e transexuais (LGBTfobia) e a motivação dos odiadores pode estar no fato de a pluralidade sexual provocar desconforto àqueles contrários à liberdade pessoal dos indivíduos (PERES, 2013).

Atributos biológicos, genotípicos, fisiológicos ou físicos também são usados para justificar o discurso de ódio (racismo, sexismo, capacitismo). Estudos de gênero e intolerância permitem uma reflexão sobre as relações de poder e sobre os modos como essas convenções sociais sobre o masculino e o feminino produzem hierarquias e desigualdades. O sexismo, nesse sentido, precisa ser analisado levando em consideração a cultura patriarcal, em que mulheres são tomadas como seres de menor prestígio social tanto por homens quanto por mulheres, tanto intra-gêneros quanto entre gêneros (RIZZOTTO, SARAIVA, 2020; SARMENTO, 2013; VEIGA DA SILVA, 2014).

O racismo, por seu lugar, tem por base um conjunto de julgamentos préconcebidos que avaliam as pessoas de acordo com suas características físicas, em especial a cor da pele. É um delito de ordem coletiva, que ataca não somente a vítima, mas todo o ideal de dignidade humana (SILVA, 2012), inclusive o expresso no artigo $5^{\circ}$, inciso XLII, da Constituição Federal: "a prática do racismo constitui crime inafiançável e imprescritível, sujeito à pena de reclusão, nos termos da lei".

Pessoas com deficiência também são vítimas do ódio e discriminação, o chamado capacitismo. Ao tratar do tema, Tunes (2007) afirma que o preconceito em relação à deficiência tem raízes na própria definição do conceito de deficiência, pois o próprio ato de nomear o deficiente implica o preconceito. Logo, a afirmação da deficiência já é um preconceito. Para a autora, a noção de deficiência está associada à falta, que pode ser parcial, transitória ou absoluta. 
Outro ponto importante do capacitismo é a questão sociolinguística. Não é raro termos como retardado e mongolóide serem proliferados para humilhar e diminuir outras pessoas sem causarem espanto quanto à associação entre deficiência e inferioridade. Nesse sentido, o indivíduo com alguma deficiência sofre em sua dignidade de pessoa, sendo reduzido à condição de não cidadão, de não humano ou indigno de tratamento respeitoso e igualitário.

Afiliações relacionadas a comunidades, culturas, origem, nacionalidade ou classe social também provocam repulsa e discriminação (xenofobia, aporofobia). O estrangeirismo e a xenofobia são manifestações de ódio e hostilidade que podem ser identificadas na humilhação, constrangimento, agressão física e moral àquele que não é natural do lugar do agressor (ALBUQUERQUE JUNIOR, 2016). Implica uma desconfiança e um preconceito em relação às pessoas estranhas ao território, ao meio, à cultura a que pertence aquele que julga, que observa, que se considera como estando em seu lugar.

O termo aporofobia referencia o desprezo, o ódio, o temor e a rejeição às pessoas pobres, desamparadas etc. Cortina (2017) reforça que a verdadeira atitude que sustenta muitos comportamentos supostamente racistas e xenófobos não é, em realidade, a hostilidade aos estrangeiros, às pessoas que pertencem a uma etnia diferente da maioria, mas sim a repugnância e o temor aos pobres, a pessoas que não apresentam o aspecto respeitável de quem tem aquilo.

O ódio político-partidário e a intolerância religiosa estão ligados às disposições atitudinais, crenças ou modos de pensar (BROWN, 2017) de representantes políticos, indivíduos ou grupos, filiados ou não, a partidos políticos ou ideologias políticas, crentes ou não crentes. No caso do político-partidário, a manifestação pode acontecer de forma extremista e violenta, com recursos sofisticados, travestida de oposição política. Os destinatários, em sua maioria, são adversários políticos ou indivíduos com afinidades ideológicas divergentes. O ódio pode ser usado como estratégia de ataque coordenado, sob o argumento da proteção moral da família tradicional e de bandeiras conservadoras, provocando ataques constantes à dignidade de grupos não dominantes ou vulneráveis (SCHAFER et al., 2015).

O discurso de ódio no contexto religioso, também conhecido como intolerância religiosa, pode ser reconhecido em atitudes de discriminação, preconceito e violência em relação àqueles que são considerados dissidentes, heterodoxos, agnósticos, seculares e ateus (CONSANI, 2015). Pode ser manifestado em 
práticas fundamentalistas e extremistas, incluindo disseminação de conteúdos que ameaçam ou promovem ações contra os direitos civis (seculares), insultando ou expressando desprezo com base em argumentos religiosos.

O discurso de ódio por aparência e o etarismo estão ligados às questões de conduta e ao corpo em evidência. O discurso de ódio por aparência reflete uma cultura pautada num estereótipo de beleza em que não há espaço para flacidez e excesso de gordura. A gordura, a flacidez ou a moleza são tomadas como símbolos da indisciplina, do desleixo, da preguiça, da falta de investimento do indivíduo em si mesmo. Também chamado de gordofobia, esse tipo de discurso aparece, por vezes, escondido na associação entre beleza, saúde e potência (NOVAES, 2013).

No caso do etarismo, a associação preconceituosa entre idade e capacidade do indivíduo interfere no tratamento que as pessoas idosas recebem numa seleção de emprego, nos acessos aos espaços públicos e na aceitação de si mesmo e dos outros (BYTHEWAY, 2005, p. 14). O preconceito e a discriminação contra o idoso também pode ser chamado de ageísmo, idadismo ou velhismo e reflete uma resistência frequente ao curso natural do envelhecimento, associando as pessoas de mais idade a seres mais frágeis e improdutivos.

\section{Redes sociais digitais, Facebook e discurso de ódio}

As redes sociais digitais se tornaram um locus fundamental para observação e compreensão da cultura digital e da democracia na sociedade contemporânea e servem como teste de hipóteses em várias áreas do conhecimento. Esses espaços, anteriormente chamados de "sites de redes sociais", ganharam conceitos mais robustos e passaram a ser tratados como plataformas que conectam interagentes, anunciantes e desenvolvedores, proporcionando efeitos de rede em que o valor aumenta para todas as partes à medida que mais pessoas o utilizam (HELMOOD, 2019; VAN DIJCK et al., 2018; DAVIS, 2020).

Van Dijck et al. (2018) consideram como plataforma infraestruturas digitais estruturadas por dados, organizadas por algoritmos e governadas por relações de propriedade, com normas e valores inscritos em seus desenhos. Os autores usam do termo "Plataformização da Sociedade" para se referir à inextricável relação entre plataformas online e estruturas societais, referindo-se à dependência que os setores sociais (transporte, educação etc.) têm em relação às empresas de tecnologia. 
Para Helmood (2019), a plataformização da web está associada à ascensão das APIs (Application Programming Interface - interface de programação de aplicações), que permite a troca de dados entre os aplicativos e a criação de novas aplicações, ampliando espaços externos das redes sociais digitais. 0 uso de APIs possibilita que empresas como Facebook e Twitter, por exemplo, empreguem extensões e formatem os dados externos para mercantilizar as atividades dos interagentes e conteúdos da web e de aplicativos (HELMOOD, 2019, p. 67).

Davis (2020) trata de como as affordances das plataformas interferem na dinâmica social, permitindo e restringindo o envolvimento dos interagentes. O design das plataformas molda como uma tecnologia funciona e com qual efeito o faz. Consequentemente, a própria tecnologia passa a solicitar, exigir, encorajar, desencorajar, recusar e permitir a ação social.

Nesse contexto de plataformização da web, dataficação, mercantilização e seleção algorítmica, as empresas que administram as redes sociais digitais detêm dados de seus interagentes em uma escala sem precedentes, o que as coloca como centro nas discussões sobre governança, transparência, privacidade e segurança, liberdade de expressão, ética etc. Uma dessas empresas é o Facebook, rede social criada por Mark Zuckerberg, em 2004, e que tem como missão "dar às pessoas o poder de criar comunidades e aproximar o mundo" (FACEBOOK, 2020).

A empresa de Zuckerberg tem sofrido pressão social de anunciantes e de governos quanto a sua política de dados e moderação de conteúdo impróprio, incluindo a moderação de discurso de ódio online ${ }^{1}$. A plataforma diz remover "conteúdos de ataque com base em raça, etnia, nacionalidade, religião, orientação sexual, gênero, [...]" (FACEBOOK, 2017), mas não é o que acontece integralmente na prática.

Davis (2020, p. 191) afirma que embora o Facebook proíba o racismo e a intolerância em seus termos de serviço, seus algoritmos são desenvolvidos para extrair e transformar dados em informações para clientes pagantes, o que pode manter tendências políticas fortes, conectadas ou separadas da intenção do designer da plataforma. Outro aspecto levantado pela autora é que a plataforma não apenas promove conteúdo com apelo de massa, mas também chama a atenção para aqueles que já ocupam um espaço simbólico

1 Ver mais em: <https://www.nytimes.com/2020/06/26/business/media/Facebook-advertisingboycott.html>. 
e significativo na rede - o chamado rich get richer (enriquecendo o mais rico), ou seja, os interagentes são incentivados a se envolver com conteúdo que já chamou a atenção e desestimulados a se envolver com conteúdo que ganhou pouca notoriedade.

Ben-David e Fernandez (2016) apontam que os recursos tecnológicos e a lógica corporativa das plataformas interferem na dinâmica das performances de ódio e contribuem para a percepção da retórica do ódio como informação legítima. Para os autores, a lógica do algoritmo não é neutra e pode discriminar de acordo com os interesses da empresa que administra a mídia social. O ódio, portanto, não surge fortuitamente de eventuais discordâncias, mas é também o resultado inevitável do funcionamento das plataformas.

\section{As publicações de Jair Bolsonaro no Facebook}

O primeiro esforço dessa pesquisa foi observar a página de Jair Bolsonaro - à época com um pouco mais de quatro milhões de seguidores - a fim de encontrar algum vestígio de incitação ao ódio ou de discurso de ódio propriamente dito nas publicações. Dos 1.548 posts feitos entre os anos de 2013 e 2016, foram eleitos os cinco com o maior engajamento (soma de comentários, reações, curtidas e compartilhamentos) para uma primeira observação. Embora sejam consideradas de vaidade (ROGERS, 2018), para os fins deste artigo, estas métricas de engajamento serviram para validar a fanpage como objeto de estudo e sinalizar como algumas postagens da página, claramente, incitavam a produção e reprodução do discurso de ódio.

O post com maior engajamento foi publicado em $1^{\circ}$ de julho de 2015 e apresentava um link com a lista dos deputados que votaram contrários à redução da maioridade penal. A publicação fazia menção à presidente Dilma Rousseff, PT, PSOL e PC do B, considerando-os promotores de uma cultura de dependência entre os menores infratores com o intuito de manter benefícios financeiros às instituições que trabalham com crianças e adolescentes em situação de vulnerabilidade. A segunda postagem analisada consistia numa fotografia de uma senhora segurando um cartaz com frases de apoio ao período do Regime Militar, exigindo a exclusão/expulsão de Dilma e do PT do país. Publicada em 4 de abril de 2014, essa postagem promovia uma campanha negativa à presidente Dilma Rousseff em ano de pleito eleitoral.

Outro post com grande engajamento continha um vídeo de Bolsonaro ao lado da filha Laura, menor de idade, explicando os motivos pelos quais não iria matricular seus filhos em escolas públicas. Na ocasião, Bolsonaro 
responsabilizou o governo do PT e os órgãos de Direitos Humanos pela crise da educação brasileira. O político acusou o ensino público de querer subverter crianças e adolescentes por meio de uma cartilha que estimulava uma erotização precoce e apologia a práticas homoafetivas: o chamado Kit Gay.

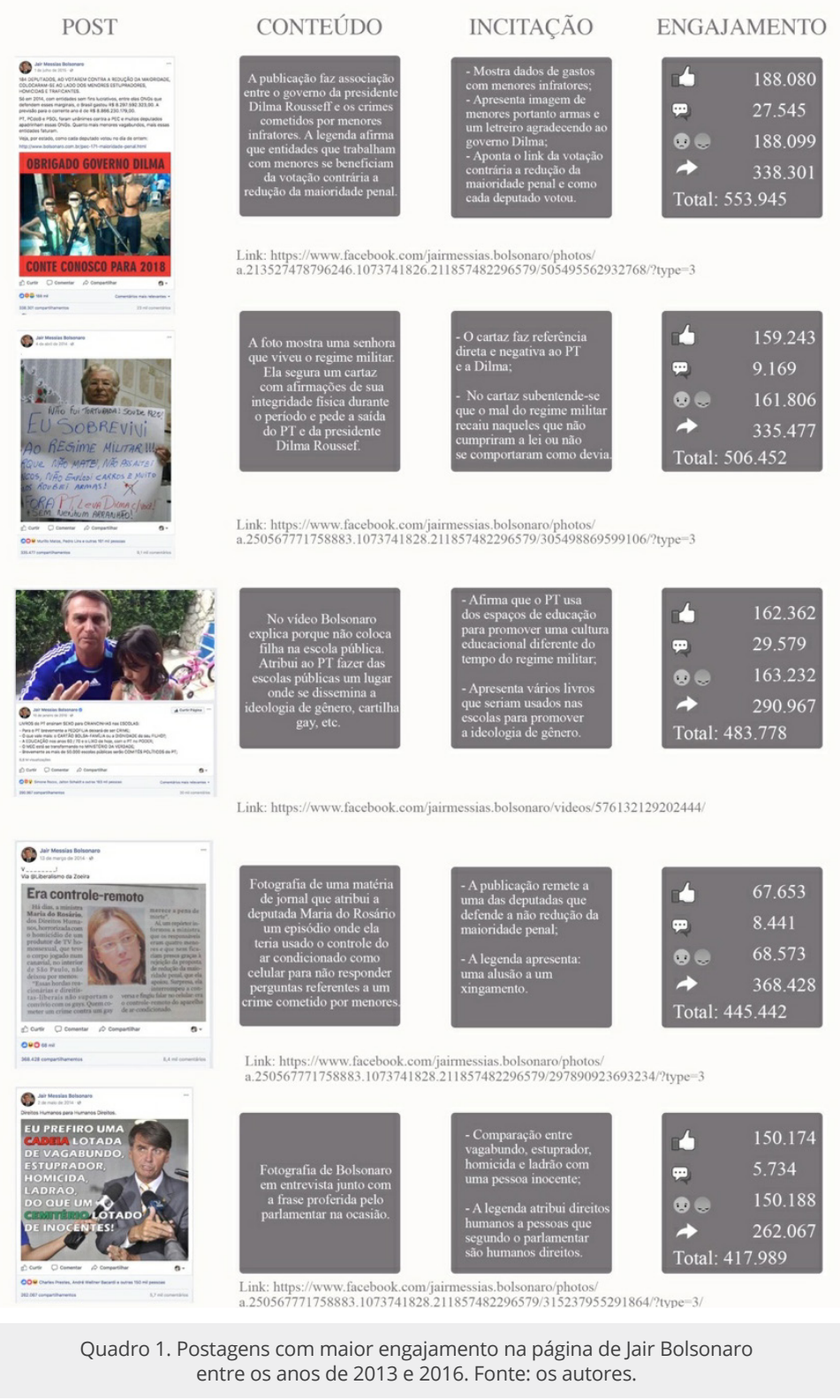


Em outra postagem, uma suposta matéria afirmava que a parlamentar Maria do Rosário usou um controle remoto como celular para não responder perguntas sobre crimes cometidos por menores. O site e-farsas averiguou o fato e constatou se tratar de uma brincadeira realizada pelo humorista Joselito Muller, sem nenhuma veracidade. A publicação foi interpretada como verdadeira e reverberou uma quantidade significativa de comentários ofensivos à deputada, utilizando de linguagem chula e sorrateira. O quinto e último post reforçava uma das bandeiras de campanha de Jair Bolsonaro: “Direitos Humanos para Humanos Direitos". A publicação comparava pessoas, dividindo-as em bandidos e inocentes, entre os que mereciam cadeia e os que precisavam de segurança.

Tais postagens, como se pode notar, carregam em si mesmas uma intencionalidade de comunicação de um discurso de ódio. Elas ilustram, também, a necessidade de se estudar como páginas de figuras públicas podem se revelar espaços simbólicos e significativos do discurso de ódio e as controvérsias protagonizadas pelas plataformas em relação à moderação desse tipo de conteúdo.

No entanto, não cabe neste artigo uma análise mais aprofundada da inferência de Bolsonaro na dinâmica de ódio por meio de suas publicações, nem a insuficiência do Facebook em fazer valer sua política de discurso de ódio. A intenção deste artigo é identificar os tipos e formas de discursos de ódio produzidos pelos seguidores da página, o que acarreta maior esforço metodológico na mineração e análise dos comentários externalizados, como se verá a seguir.

\section{Coleta e Mineração de Texto}

A coleta dos dados usou do software descontinuado Netvizz para recuperar todos os comentários da fanpage de Bolsonaro desde o início de sua atuação oficial no Facebook em 2013 até 31 de dezembro de 2016, o que resultou num total de 3.819 .909 sentenças. O Netvizz gerou arquivos em extensão .tab - comments - no qual agrupou o conteúdo das publicações realizadas por Bolsonaro e os comentários elaborados pelos seguidores. Foram preservados para esse estudo o anonimato e a privacidade dos interagentes. 
Cabe ressaltar que o Netvizz traz consigo, para este trabalho, não só uma perspectiva pragmática de extração de dados, mas também o debate sobre a ética envolvida no uso desses dados. Da mesma forma, Rieder (2013) nos chama atenção para o desenvolvimento do software com o intuito de explorar a API do Facebook, questionando o tratamento que a plataforma oferece aos dados fornecidos pelos interagentes, incluindo questões de privacidade e a forma como outros aplicativos podem acessar e fazer uso das informações dos indivíduos que estão no Facebook.

Após a extração, os dados passaram por pré-processamento no qual foram removidos os comentários duplicados, registros vazios e URLs. Um código em linguagem $\mathrm{C}^{2}$ desenvolvido exclusivamente para esta pesquisa sincronizou os termos, transformando os caracteres maiúsculos em minúsculos, preservando os emojis e descartando os comentários que tinham alguma mídia (vídeo, som, gif), já que o arquivo original disponibilizado pelo Netvizz não recupera esse tipo de conteúdo. Além disso, o código também foi usado para a Mineração Textual, seguindo esta ordem:

1. Os comentários recuperados passaram por uma filtragem, permanecendo os que continham uma ou mais palavras-chave elencadas no dicionário de termos deste artigo (conforme disponível no Apêndice ${ }^{3}$ ).

2. Cada palavra-chave está associada a um dos 10 tipos de discurso de ódio eleitos para essa pesquisa (sexismo, LGBTfobia, aporofobia, xenofobia, racismo, intolerância religiosa, etariedade, aparência, político-partidário e capacitismo). Ao reconhecer uma dessas palavras/ expressões em um dos comentários recuperados, o código classificou a sentença conforme os tipos supracitados.

A mineração dos 3.819.909 comentários revelou 78.004 sentenças que continham um ou mais termos de ódio. Esse primeiro resultado será explorado na descrição do gráfico 1.

2 Disponível em: <https://github.com/betiato/Filtragem-de-dados-extraidos-netvizz?fbclid=IwAR1W LOoqizxFqWNQnuMEXZecKHp0-0x4dAW-rMD3Emlcb9bbxPcwNOBemo0>. Detalhes do funcionamento estão em: <https://acervodigital.ufpr.br/handle/1884/54944>.

3 Para o dicionário de termos foram consideradas as palavras, expressões e epítetos que explicitamente induziam ao ódio ou tinham relação direta com algum grupo de característica protegida (SILVA; SAMPAIO, 2017). 


\begin{tabular}{|c|c|}
\hline Tipo de discurso de ódio & Palavras-chave e expressões de ódio recuperadas \\
\hline Político/partidário & $\begin{array}{l}\text { "petralha"/ " "petralha safada" / "coxinha"/"coxinha burro" / "comu- } \\
\text { nista"/ "comunista safado" / "fascista"/ /"coxinha fascista" /"político } \\
\text { ladrão" /"compra votos" / "petista vagabundo" / "elite golpista" / } \\
\text { "esquerda caviar" / "esquerdopatas"/ "esquerdosos"/ "vermelhos } \\
\text { pervertidos"/ "esquerdistas"/ "maconheiro libertário"/ " "Socialista } \\
\text { Psicopata"/ "vai pra Cuba"/ / "Volta pra Cuba" }\end{array}$ \\
\hline Sexismo & $\begin{array}{l}\text { "vadia"/ "safada" / "mal comida" /"coisa de mulherzinha" / "falta de } \\
\text { rola" / "falta de pica" / "cara de puta" / "odeio mulher" / "feminazi" } \\
\text { / "tinha que ser mulher"/ "chifrudo"/ "vaca ordinária"/ "quenga"/ } \\
\text { "biscate"/ "piriguete"/ /periguete"/ "piranha" }\end{array}$ \\
\hline LGBTQIfobia & $\begin{array}{l}\text { "boiola" / "baitola" / "cara de traveco" / "voz de traveco" /"queima } \\
\text { rosca" / "meio afeminado" / "coisa de boiola" / /parece uma bixa" / } \\
\text { "jeitinho de gay"/ /"jeito de gay"/"bichona"/"bixona"/"pau no toba"/ } \\
\text { "homossexual nojento"/ "pervertidos"/ "viadagem"/ "vira homem" }\end{array}$ \\
\hline Racismo & $\begin{array}{l}\text { "não sou tuas nega" / "tinha que ser preto" / "da cor do pecado" / } \\
\text { "preto é foda" / "nego é foda" / "cara de macaco"/"esse macaco"/ } \\
\text { "preto safado"/ "negro fedido"/ "nego fedido"/ /"macaco"/ "bugre"/ } \\
\text { "índio preguiçoso"/ /índio vagabundo"/ "indiarada" }\end{array}$ \\
\hline Aporofobia & $\begin{array}{l}\text { "Bolsa esmola" / "pobraiada" / "bandido favelado" / "favelado" / } \\
\text { "filho de papai" / "coisa de pobre" / "mendigo fedido" / "trabalhar } \\
\text { vagabundo"/ " "pobre ignorante"/ "fracassado"/"pobretão"/ "bar- } \\
\text { riga suja" }\end{array}$ \\
\hline Xenofobia & $\begin{array}{l}\text { "povo burro" / "nordestino vagabundo" / "muçulmano bomba" } \\
\text { / "homem bomba"/ "baianice" / "baianada" / "tudo terrorista" / } \\
\text { "volta pra sua terra" / "caiçara folgado" / "caipira burro" / povo da } \\
\text { roça / "bando de jumento"/ "invasão haitiana"/ "volta para Africa"/ } \\
\text { "povinho" }\end{array}$ \\
\hline Deficiência & $\begin{array}{l}\text { "retardado mental" / "tem down" / "aleijado" / "aleijado"/ "um } \\
\text { demente" / "uma demente"/ "leproso" / "aidético" / "coisa de retar- } \\
\text { dado" / "deficiente mental" / "é autista" /"parece cego"/ / débil men- } \\
\text { tal"/ "abestado"/ "mosca morta"/ /mongoloide"/ "imbecil" }\end{array}$ \\
\hline Etariedade & $\begin{array}{l}\text { "Velho burro" / "velho babão" / "velho nojento" / "velho safado" / } \\
\text { "velho tarado" / "coroa fogosa" /"velho pra isso" / "velha pra isso"/ } \\
\text { "não tenho idade" / "jovem burro" / "adolescente maconheiro" }\end{array}$ \\
\hline Intolerância Religiosa & $\begin{array}{l}\text { "crente do rabo quente" / "crente do cu quente" / "odeio crente" } \\
\text { / "sem Deus no coração" / "bando de crente"/ "padre pedofilo" / } \\
\text { crente safado / crentona / "chuta que é macumba"/ falso profeta } \\
\text { /"macumbeir"/"crentaiada"/"satanista"/"pastorzinho de merda"/ } \\
\text { "herege" }\end{array}$ \\
\hline Aparência & $\begin{array}{l}\text { "Narigud" / "fazendo gordice" / "cabelo ruim"/ "cabelo de bombril" } \\
\text { / "gorda escrota"/ / gordo escroto" / "feia pra caralho"/ "anão de } \\
\text { jardim"/ "cão chupando manga"/ "bucha de canhão"/ "peluda"/ } \\
\text { "cara imunda"/ "baranga"/ "tribufu"/ / "mocreia" }\end{array}$ \\
\hline
\end{tabular}

Quadro 2. dicionário de termos usados nos processos de mineração textual. Fonte: os autores com base no trabalho de Silva e Sampaio (2017).

Em seguida, devido ao grande volume de comentários contendo um ou mais termos de ódio, foi realizado um cálculo amostral multiestágio sistematizado (PÉLLICO NETTO; BRENA, 1993) para elencar os comentários que seriam codificados manualmente para identificar a forma como os interagentes manifestaram o seu ódio. Para tanto, utilizou-se da seguinte fórmula: 


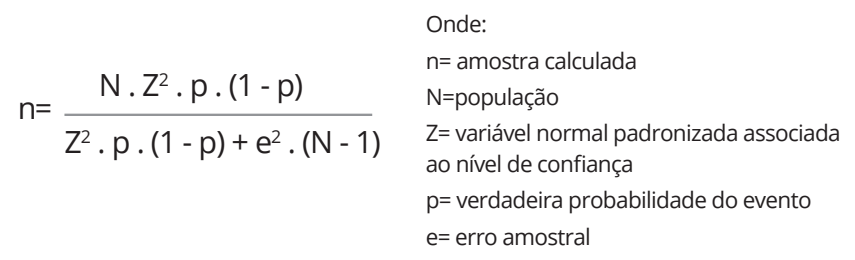

O estágio de amostragem foi definido por anos, com grau de confiabilidade de $95 \%$ e erro amostral de 5\%, chegando ao seguinte resultado:

\begin{tabular}{|l|l|l|l|}
\hline \multirow{3}{*}{ Parlamentar } & Ano & Total de Comentários & $\begin{array}{l}\text { Amostragem Primária } \\
(95 \% \text { de confiabilidade e } \\
5 \% \text { de erro amostral) }\end{array}$ \\
\hline \multirow{3}{*}{ Jair Bolsonaro } & 2013 & 288 & 165 \\
\cline { 2 - 5 } & 2014 & 10.673 & 371 \\
\cline { 2 - 5 } & 2015 & 16.668 & 376 \\
\cline { 2 - 4 } & 2016 & 50.375 & 382 \\
\hline \multirow{2}{*}{ Quadro 3. Estágio de amostragem. Fonte: os autores }
\end{tabular}

\section{Análise de Conteúdo dos comentários}

O cálculo amostral multiestágio sistematizado resultou num total de 1.294 comentários que foram examinados por meio de Análise de Conteúdo (NEUENDORF, 2002) por três codificadores previamente treinados até alcançarem confiabilidade pelo coeficiente Kappa de Cohen de 0.646. O valor do coeficiente de concordância de Kappa pode variar de 0 (zero) até 1. Quanto mais próximo de 1 for seu valor, maior é o indicativo de que existe uma concordância entre os codificadores e, portanto, maior confiabilidade entre eles. No caso, o valor de 0.646 indica confiabilidade razoável (aceitável) 4 .

O treinamento aconteceu em três etapas: na primeira, os três codificadores, em conjunto, classificaram 50 comentários baseados em livro de código, conforme resumido na Figura 2; na segunda etapa, cada codificador analisou outros 50 comentários diferentes de forma individual e as impressões foram compartilhadas; e, por fim, foram eleitos, de forma aleatória, outros 50 comentários que foram codificados por cada um dos pesquisadores separadamente até alcançar o coeficiente necessário para a codificação da amostra multiestágio sistematizada. Os 1.294 comentários foram divididos entre os codificadores de maneira equivalente, sendo que nenhum comentário foi descartado.

4 Quando o teste de confiabilidade entre codificadores alcança um índice adequado, não é necessário o desempate da codificação por um terceiro codificador. Para mais sobre o funcionamento desse tipo de teste, ver Sampaio, Lycarião (2018). 


\begin{tabular}{|c|c|}
\hline $\begin{array}{l}\text { Forma de discurso } \\
\text { de ódio }\end{array}$ & Descrição \\
\hline Insultos e Xingamento & Insultos, epítetos depreciativos e linguajar chulo. \\
\hline Incitação à Violência & $\begin{array}{l}\text { Manifestações que faziam ameaças ou chamadas para a vio- } \\
\text { lência contra indivíduos ou grupos, incluindo também conte- } \\
\text { údo que advogassem para ações violentas contra indivíduos } \\
\text { ou grupos de características protegidas. }\end{array}$ \\
\hline Ameaça & Ameaças sem violência explícita. \\
\hline $\begin{array}{l}\text { Superioridade, } \\
\text { Normalidade ou } \\
\text { inferioridade }\end{array}$ & $\begin{array}{l}\text { Conteúdo que colocava em questão os direitos de um grupo em } \\
\text { relação a outro, afirmando que o grupo "inferior" deve subme- } \\
\text { ter-se à vontade ou adotar algumas das características (idioma/ } \\
\text { religião/ orientação sexual) do grupo "superior". }\end{array}$ \\
\hline $\begin{array}{l}\text { Estereótipos e } \\
\text { Generalizações }\end{array}$ & $\begin{array}{l}\text { Conteúdo argumentando que se teria certas características e/ } \\
\text { ou comportamentos negativos tidos como desprezíveis e antis- } \\
\text { sociais apenas por ser membro de um grupo, ou que todos os } \\
\text { membros os têm, justificando a discriminação e invalidando os } \\
\text { seus pedidos de direitos ou igualdade de tratamento. }\end{array}$ \\
\hline Exclusão/ Expulsão & $\begin{array}{l}\text { Conteúdo que afirmava que o grupo majoritário é o "dono" } \\
\text { legítimo do país/espaço e, por conseguinte, capaz de invali- } \\
\text { dar reivindicações pelos direitos de determinada minoria com } \\
\text { base no argumento de que o país/espaço pertence a eles, bem } \\
\text { como argumentos pautados em estatuto tolerado, primazia } \\
\text { política ou que exigem a expulsão de um grupo do território, } \\
\text { com ou sem motivos específicos para tal ou por divergências } \\
\text { de opiniões. }\end{array}$ \\
\hline Animal/ Sub-humano & $\begin{array}{l}\text { Conteúdo que comparava ou fazia co-relação entre pessoas ou } \\
\text { grupos a animais, pragas ou sub-humano. }\end{array}$ \\
\hline Histórico & $\begin{array}{l}\text { Conteúdo que desqualificava os pedidos de direitos ou justi- } \\
\text { ficava a discriminação, maus tratos ou ações contra pessoas } \\
\text { ou grupos com base em atos ou injustiças feitas ao longo da } \\
\text { história. }\end{array}$ \\
\hline Extremismo Religioso & $\begin{array}{l}\text { Conteúdo que ameaça ou promove ações contra os direitos civis } \\
\text { (seculares) de pessoas ou grupos, insultando ou expressando } \\
\text { desprezo com base em argumentos religiosos. }\end{array}$ \\
\hline $\begin{array}{l}\text { Conspiração/ } \\
\text { Inimigos da Nação }\end{array}$ & $\begin{array}{l}\text { Conteúdo que implica discurso de ódio na forma de acusação, } \\
\text { conspiração contra o país/sociedade, servindo a interesses mali- } \\
\text { ciosos. Conteúdos que implicam que determinada pessoa ou } \\
\text { grupo não é líder, mas inimigo do Estado/pessoas/sociedade, ou } \\
\text { que eles são uma ameaça ou culpados pela má imagem do país. }\end{array}$ \\
\hline Direitos Negados & $\begin{array}{l}\text { Conteúdo que disputa ou nega direitos civis ou políticos de } \\
\text { membros de grupos minoritários, incluindo os direitos de repre- } \\
\text { sentação política, atividade política, direito de manifestação, } \\
\text { direito de comparecer ou falar em público, sobre o fundamento } \\
\text { de que eles são uma minoria. }\end{array}$ \\
\hline Discriminações Gerais & $\begin{array}{l}\text { Conteúdos discriminatórios que não se encaixaram em } \\
\text { nenhuma das categorias citadas, mas que contenham men- } \\
\text { sagens destinadas a aterrorizar, humilhar, degradar, abusar, } \\
\text { ameaçar, ridicularizar, humilhar e discriminar com base na raça, } \\
\text { etnia, religião, orientação sexual, origem nacional ou gênero, } \\
\text { expressar preconceito e desprezo, promover ou apoiar a dis- } \\
\text { criminação, o preconceito e a violência. }\end{array}$ \\
\hline
\end{tabular}

Quadro 4. Formas de discurso de ódio. Fonte: os autores. 


\section{Tipos e formas de discurso de ódio no Facebook de Jair Bolsonaro}

O primeiro resultado notável reside no aumento exponencial de comentários com um ou mais termos odientos propostos pelo dicionário eleito para esta pesquisa. Em 2013, foram recuperados 288 comentários; em 2014, foram 10.673; em 2015, foram 16.668; e em 2016, o número chegou a 50.375. No ano de maior incidência, Bolsonaro apareceu na mídia como protagonista de várias declarações homofóbicas, xenofóbicas, misóginas, contrárias à presidente Dilma e ao PT, incluindo o discurso na votação do processo de impeachment na Câmara, quando fez referência a um coronel militar da época da ditadura apontado como torturador.

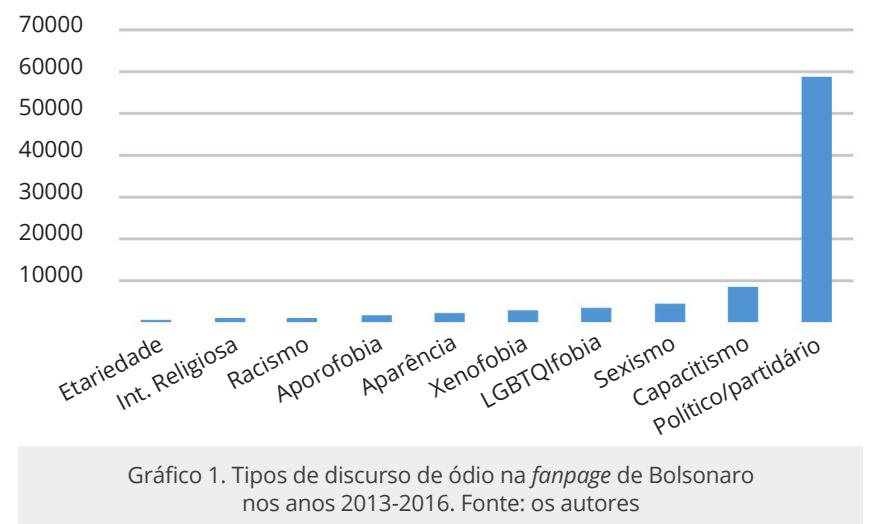

$\mathrm{Na}$ análise, todos os tipos de discurso de ódio abordados foram encontrados. Em maior ou menor número, a página apresentou manifestações odientas para todos os grupos de pessoas com características protegidas aqui estudadas. Todavia, o discurso de ódio político-partidário foi notadamente o mais presente, representando $74 \%$ do total. O percentual expressivo desse tipo de discurso pode ser justificado por alguns motivos: (a) trata-se de uma página de ator político; (b) o recorte temporal compreende visível momento conturbado do cenário político nacional, com o pleito de 2014 bastante acirrado entre Dilma Rousseff e Aécio Neves. Porém, isso também pode significar uma necessidade de readequação de categorias, como discutiremos na conclusão. Manifestações de abuso contra pessoas com deficiência física ou mental (10\%) apareceram em segundo lugar, revelando que, na circulação de conteúdos 
online é corriqueiro o uso de expressões ofensivas em relação às pessoas com deficiência. Os comentários rotulavam quem se manifestava com pensamento contrário ao de Bolsonaro como seres com problemas mentais, com destaque para expressões como retardado, demente, imbecil e mongolóide.

Sexismo (5\%), LGBTfobia (3,5\%) e xenofobia (3\%) tiveram números semeIhantes de expressões. Por aparência (2,5\%), aporofobia (1\%), racismo (0,5\%), intolerância religiosa $(0,4 \%)$ e etariedade $(0,1 \%)$ completam o gráfico. Nesse ponto, o que chamou a atenção dos pesquisadores foi a baixa incidência de comentários racistas, o que levou a duas possibilidades: os termos do dicionário usados para mineração foram insuficientes para identificar o discurso de ódio racial ou o processo de moderação de conteúdo do Facebook removeu os comentários da página. Não há como confirmar.

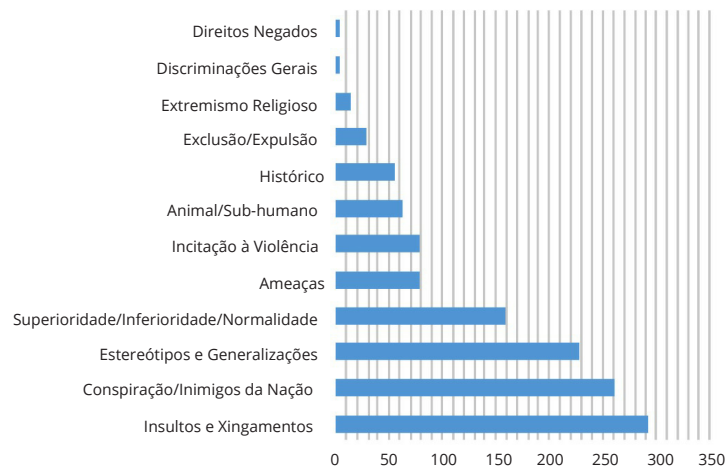

Gráfico 2. Formas de discurso de ódio na fanpage de Bolsonaro nos anos de 2013-2016. Fonte: os autores.

Insultos e xingamentos foram a forma mais usada para a manifestação de discurso de ódio online, reduzindo a sanidade do debate por meio de ataques gratuitos entre os comentadores: "Lixo de gente essa bichona desqualificada" (ID 0003/2013)5; "É teu cérebro vazando, seu mentiroso imbecil picareta!!!!" (ID 111211/2016). Nessa acepção, os alvos frequentes foram o próprio parlamentar, seus opositores políticos e outros comentadores.

Os comentários classificados nessa categoria continham poucos caracteres, limitando-se a poucas palavras e a uma agressão direta. O termo comunista foi associado àqueles que comungam de uma ideologia que visa a destruição 
das famílias, dos valores cristãos e do país. Isto posto, PT, PSOL e PC do B foram partidos destinatários desse tipo de insulto, bem como Dilma, Lula e seus apoiadores.

Conspiração/Inimigos da Nação foi a segunda forma mais utilizada de discurso de ódio. Nesse caso, os comentadores atribuíam aos partidos de esquerda supracitados o protagonismo da crise econômica e do esfacelamento do país nos últimos anos; dão a Dilma, Lula, Jean Wyllys, Maria do Rosário e Jandira Feghali, entre outras figuras de esquerda, o título de comunistas e ladrões, agindo de forma organizada para transformar o Brasil numa ditadura comunista, semelhante ao que acreditam acontecer em Cuba e na Venezuela. Fernando Henrique Cardoso e o PSDB também são acusados de conspiração para alternância de poder.

Também nessa categoria, a Rede Globo de Televisão foi rotulada pelos seguidores de Bolsonaro como inimiga da nação, sobretudo quando emitia opinião contrária à do parlamentar, quando apoiava causas LGBTQIA+ ou dava voz a acusações envolvendo Bolsonaro ou algum de seus apoiadores: "A rede esgoto 'GLOBO' ja comecou com o kit gay ja faz tempo... E o pessoal achava engracado. O Brasil ja virou um puteiro. O pais das maravilhas, onde se vota para partido comunista e nisso que da" (ID 2112/2014). A Conferência Nacional dos Bispos do Brasil (CNBB) e a Ordem dos Advogados do Brasil $(\mathrm{OAB})$ também são acusadas de conspiração junto ao governo petista com o intuito de acabar com o Brasil.

Verificou-se, também, que os estereótipos e generalizações procuraram marcar a diferença entre o comentador e o destinatário. A intencionalidade desse aspecto, por sua vez, parece estabelecer um distanciamento entre classes sociais, espectros ideológicos políticos, de cor/raça, de orientação sexual etc. Os usuários se referiam aos grupos e/ou pessoas de maneira generalista, reduzindo a vítima à sua visão limitada de mundo, impondo conotação negativa a toda uma comunidade. Os comentários classificados nessa categoria reforçaram preconceitos do tipo todo petista é corrupto, todo pastor é ladrão, toda feminista é mal-amada, todo pobre é vagabundo, todo gordo é preguiçoso, todo velho é nojento, e assim por diante.

Por outro lado, a forma Superioridade/Inferioridade/Normalidade marca a posição de fala do comentador em comparação às pessoas e comunidades historicamente marginalizadas. A maioria dos haters se colocaram como 
alguém melhor, mais bem preparado, escolhido, limpo, distante e superior à vítima, respaldando-se nas declarações de Bolsonaro e em dogmas religiosos e políticos.

A corrupção (comprovada ou não) de atores políticos de esquerda legitimou a posição de inferioridade desse espectro ideológico, ao mesmo tempo que enalteceu a superioridade de Bolsonaro por nunca ter se envolvido em escândalos de improbidade administrativa. À época das manifestações pró e contra o impeachment da então presidente Dilma, a polarização política deu margens a um discurso de ódio baseado na posição de fala. Nesse sentido, as ações de um serviam para desqualificar o outro:

Aí está a diferença nos coxinhas, somos respeitados quando nos manifestamos não quebramos o patrimônio público nem vidraças e respeitamos a lei e a nossa PM o resultado é que eles também nos respeitam. Esses são os verdadeiros brasileiros. Obrigado (ID 19772/2016).

Os comentários odientos na forma de Extremismo Religioso faziam predileção a bandeiras pró-família por meio de um discurso contra ativistas homossexuais e feministas, praticantes e defensores de religiões de matriz africana e os chamados hereges. Temas sensíveis como legalização do aborto, ecumenismo, casamento homoafetivo e igualdade de gênero foram tratados à luz da Bíblia e de preceitos cristãos, com o uso de textos sagrados para acusar, ofender e amaldiçoar os não cristãos ou apoiadores de bandeiras progressistas.

Outras categorias como Incitação à Violência, Ameaça e Animal/Sub-humano tiveram números semelhantes e formas muito agressivas de discurso de ódio. Tanto ameaças quanto incitação à violência, explicitamente, incitavam comportamentos que ultrapassavam as fronteiras do online e poderiam se concretizar em atitudes na vida real. Os resultados mostram como a Internet, nesse caso, o Facebook, possibilita um maior acesso à informação, treinamento e desenvolvimento de discursos e crimes de ódio, dando audiência aos discursos extremistas e permitindo recrutar e coordenar atividades violentas: "Quem é de Aju ai e quer bater de frente com os esquerdistas no Iphan?" (ID 53170/2016).

Entre as palavras que configuraram discurso de ódio na forma de Animal/Subhumano, estão: anta, merda, lixo, burro, verme, bosta, vaca e ratos. Comentários atrelaram à Dilma o rótulo de anta, utilizando do codinome Dilmanta a fim de 
atacar a competência intelectual da então presidente. Ao povo brasileiro, foram atribuídos os nomes merda e burro. À classe política, sobretudo aos políticos de esquerda, adjetivos depreciativos como vermes, ratos e lixo.

Comentários com base em fatos, figuras e momentos históricos e os que pedem Exclusão/Expulsão foram identificados em menor número. Na página de Bolsonaro, o tempo do Regime Militar era encarado com saudosismo e referenciado como um momento histórico importante para o país. Os comentários homofílicos (a favor da visão de Bolsonaro) afirmavam que tal período era retratado de maneira equivocada no ensino, sendo artimanha doutrinadora do que os interagentes chamariam de conspiração comunista, formada pelos partidos de esquerda, a Igreja Católica e as universidades. Nesse sentido, insistiam que a tortura e a violência do regime só foi empregada contra os que de fato procuraram conflito com o governo, foram exemplos de maus cidadãos e coordenavam a implantação de uma ditadura comunista. Figuras históricas, como Che Guevara, Karl Marx, Antônio Gramsci e Simone de Beauvoir, eram utilizadas para desqualificar os pensamentos de esquerda, sendo referenciados como exemplos de derrotados e usurpadores da nação.

Quando os comentários pediam a expulsão ou a exclusão da pessoa ou grupo do convívio social e/ou do Brasil, os destinos indicados eram países como Cuba, Venezuela e China. “Vá esquerdar em outro lugar! Ótima! Poderia ser... Vá esquerdar em Cuba! Não podemos deixar esta minoria de esquerdopatas (corruptos) dominar o Brasil!!" (ID 119321/2015). Essas exclusão e expulsão, em sua maioria, eram dirigidas aos líderes do PT e apoiadores de partidos e políticas tidas como de esquerda.

Entre as discriminações que pediam o fim de alguns direitos, ou que negavam direitos às minorias, fica claro um ataque à Dilma Rousseff (no episódio da manutenção de seus direitos políticos), às cotas raciais e à causa LGBTQIA+. Os comentários versavam sobre a lógica de igualdade para todos, defendendo que negros e gays usufruiam de privilégios. As interações acusavam a comunidade LGBTQIA+ de tentar estabelecer uma ditadura gay na qual as pessoas não poderiam mais usar de sua liberdade de expressão.

As Discriminações Gerais foram atribuídas quando o comentário não se encaixava em nenhuma das outras categorias, sendo observada em raras vezes e sempre na condição de chacota e piada: "A zuera não vai parar nunca! os esquerdopatas piram! Da-Ihe zuera! da-Ihe Bolsonaro!" (ID 135/2016). 


\section{Considerações finais}

O artigo buscou analisar os comentários postados na página do Facebook de Jair Bolsonaro no período entre 2013-2016 que, explícita ou implicitamente, manifestavam discurso de ódio. $\mathrm{O}$ intuito era identificar quais os tipos e formas de discurso de ódio mais recorrentes ao longo dos anos observados. Ademais, a análise preliminar dos cinco posts com mais engajamento durante o período analisado validou a página como objeto de estudo e sinalizou como algumas postagens de Jair Bolsonaro já incitavam a produção e reprodução do discurso de ódio muito antes de sua notoriedade como Presidente da República. Por outro lado, o número de postagens analisadas não foi suficiente para avaliar se a prática era habitual na página do deputado, o que já descortina, como trabalho futuro, a possibilidade de análise dessas publicações com o propósito de verificar a existência ou não de uma correlação entre postagens e comentários.

Com a Mineração Textual e Análise de Conteúdo dos comentários, por sua vez, foi possível identificar o tipo de discurso de ódio político-partidário como o mais recorrente, com claro intuito de fomentar a agenda conservadora e extremista proposta pelo parlamentar, possivelmente já incentivando sua candidatura à presidência em 2018. Em muitos casos, a oposição política foi usada pelos seguidores da página como subterfúgio para manifestação do discurso de ódio na forma de conspiração/inimigos da nação, superioridade/normalidade/inferioridade e estereótipos e generalizações, revelando uma grande hostilidade aos partidos e atores políticos de esquerda, oponentes de Bolsonaro, sobretudo, os ex-presidentes Lula e Dilma e os deputados Maria do Rosário e Jean Wyllys.

Outro ponto relevante foi a constatação de que, num mesmo comentário de ódio político-partidário, estavam presentes manifestações de sexismo, homofobia e xenofobia, o que aponta a necessidade de abordagens mais sistêmicas na codificação, atrelando outros fatores que não só uma mineração por termos. Assim, os $74 \%$ de mensagens categorizadas como discurso de ódio político-partidário podem significar a necessidade de um refinamento das categorias de análise ao se tratar de temáticas políticas, algo que será revisado para futuras aplicações do método em tela.

Quanto às formas de discurso de ódio, Insultos e Xingamentos se destacaram num contexto de pouca argumentação e julgamentos apressados. Os comentadores estabeleceram interações superficiais, nas quais as trocas de 
ofensas entre si estavam baseadas na sua visão particular e moralista de mundo e na adesão a determinado espectro político-ideológico. Quando o discurso de ódio era voltado a figuras públicas, as formas Conspiradores e Inimigos da Nação, Estereótipos e Generalizações e Superioridade/Normalidade/ Inferioridade atribuem aos destinatários, seja o próprio Bolsonaro ou seus opositores, o papel de contraproducentes ao crescimento do país.

Na análise, quando observadas as duas categorias (tipos e formas), na dinâmica que se apresentaram, ficou evidente a desinibição dos seguidores em expor sua discriminação de forma explícita e agressiva. O conteúdo dos comentários exacerba as tensões étnicas, religiosas e raciais de forma jocosa e violenta. Bolsonaro, por sua vez, encontrou no Facebook um espaço favorável à ressonância de seu discurso oportunista e eleitoreiro. Apesar dessa pesquisa não se aprofundar na análise das postagens do parlamentar, boa parte dos comentários indicam alguma ligação com temas/episódios levantados por alguma publicação. Um dos indícios é a forte presença de frases de apoio - "é isso aí Bolsonaro" - que precedem ou antecedem alguma manifestação de ódio. Em alguns casos também é reforçado o bordão comumente defendido por Bolsonaro: "Direitos Humanos para humanos direitos".

Não obstante, o Facebook parece colaborar para a desinibição dos odiadores e acaba sendo intermediário/mediador do discurso de ódio, permitindo que os comentários odientos permaneçam e alcancem audiências, mesmo sendo de notório saber que diversos políticos de extrema direita permitem e incentivam tais discursos em suas páginas. Tal incapacidade (ou falta de disposição) da plataforma em moderar esse tipo de conteúdo pode indicar que seu interesse comercial é maior que a preocupação em proteger as pessoas.

Cabe ressaltar que houve avanços em políticas e ações do Facebook que visam controlar conteúdo impróprio desde o último ano de coleta desta pesquisa, mas falta transparência nos processos e agilidade na moderação. Defendemos que é necessário conhecer as particularidades do fenômeno a fim de encontrar alternativas ao problema sem que seja colocada em risco a liberdade de expressão, ao mesmo tempo que deve ser oferecido tratamento especial a páginas de figuras ou instituições políticas, haja vista a constatação desse e de outros estudos de que nesses espaços há grande probabilidade de interações odientas e que, sendo espaços "oficiais", isso pode ser tomado como incentivo tanto pela plataforma digital quanto pelos atores políticos envolvidos (MENDONÇA, AMARAL, 2016; SILVA, SAMPAIO, 2017; RIZZOTTO, SARAIVA, 2020). 
A abordagem metodológica deste trabalho busca apresentar rigor e transparência em um processo multiestágio, porém também pode ser refinada. No caso de pesquisas futuras, a própria coleta de dados está comprometida pelas restrições impostas pelo Facebook; a Mineração Textual, incluindo o dicionário de termos, precisa ser constantemente atualizada, já que o discurso de ódio pode estar implícito em uma miríade de termos e expressões; a Análise de Conteúdo deve contemplar os falsos-positivos, ocasiões nas quais o termo identificado como parte do discurso de ódio não tem a conotação negativa, seu significado/sentido é outro que não ofensivo ou está sendo usado para defender ou revidar o ataque, sem necessariamente ser um discurso intolerante e radical.

De toda sorte, essa pesquisa se une à agenda de pesquisa teórica e empírica sobre discurso de ódio e redes sociais digitais num esforço epistêmico e metodológico para encontrar alternativas ao fenômeno. Ao verificar os tipos e formas mais costumeiras do fenômeno no Facebook, espera-se que a plataforma amplifique seus métodos de moderação e mantenha a saúde das interações e dos valores democráticos que seus representantes e seus documentos oficiais pregam.

Luiz Rogério Lopes Silva é doutorando em gestão da Informação pela Universidade Federal do Paraná, com Bolsa CAPES, professor do departamento de Comunicação e Negócios do Centro Universitário Autônomo do Brasil (UNIBRASIL) e membro do InfoMedia (grupo de pesquisa e laboratório de mídia do PPGGI-UFPR).

luizlopescomunicacao@gmail.com

Rodrigo Eduardo Botelho Francisco é pesquisador vinculado aos programas de pós-graduação em Comunicação e em Gestão da Informação; e docente do Depto de Ciência e Gestão da Informação da Universidade Federal do Paraná (UFPR). É doutor e mestre em Ciências da Comunicação pela Escola de Comunicação e Artes da USP; com pós-doutorado na Universidad Complutense de Madrid e na Universitat Autònoma de Barcelona. É especialista em Computação - na área de Desenvolvimento de Software para Web - e em Gestão Pública pela UFSCar e pesquisador na Rede de Pesquisa Aplicada Jornalismo e Tecnologias Digitais, vinculada à Sociedade Brasileira de Pesquisadores em Jornalismo, SBPJor; e no Núcleo de Apoio à Pesquisa 
(NAP) Escola do Futuro, da USP. É criador do Sistema de Apoio à Comunicação Integrada $(\mathrm{SACl})$, um software livre de gestão convergente e colaborativa de produção midiática registrado junto ao INPI.

robotelho@gmail.com

Rafael Cardoso Sampaio é professor do Depto de Ciência Política e dos Programas de Pós-graduação em Ciência Política e em Comunicação Social da Universidade Federal do Paraná (UFPR). É presidente da Associação Brasileira de Pesquisadores em Comunicação e Política (Compolítica) e pesquisador do Instituto Nacional de Ciência e Tecnologia em Democracia Digital (INCT-DD). É colíder do grupo de Pesquisa Comunicação e Participação Política (COMPA). E doutor em Comunicação e Cultura Contemporâneas pela UFBA. Já atuou como consultor do Banco Mundial, Bertelsmann Foundation (Alemanha), Adam Smith International (Reino Unido) e já foi assessor de pesquisas do Comitê Gestor da Internet (CGI.br), Labhacker (Câmara dos Deputados) e W3C Brasil e Centro de Estudos sobre Tecnologias Web. Atualmente, realiza estágio pós-doutoral no Programa de Pós-Graduação em Ciência Política da Universidade Federal de Minas Gerais (UFMG).

cardososampaio@gmail.com

Contribuições de cada autor: Os autores trabalharam em conjunto durante todo o projeto de pesquisa. Luiz foi responsável pela fundamentação teórica e conceituação, curadoria de dados, análise formal do corpus, gestão de software, construção de figuras e tabelas e primeira redação. Rodrigo e Rafael auxiliaram na redação, revisão e edição, definição e refinamento dos procedimentos metodológicos e na análise do corpus, obtenção de financiamento e gestão de recursos.

\section{Referências}

ALBUQUERQUE JÚNIOR, D. M. Xenofobia: medo e rejeição ao estrangeiro. Cortez Editora, 2016.

BEN-DAVID, A.; FERNÁNDEZ, A. M. Hate speech and covert discrimination on social media: Monitoring the Facebook pages of extreme-right political parties in Spain. International Journal of Communication, v. 10, p. 27, 2016. 
BYTHEWAY, B. Ageism and age categorization. Journal of social Issues, v. 61, n. 2, p. 361-374, 2005.

BROWN, A. What is hate speech? Part 1: The myth of hate. Law and Philosophy, v. 36, n. 4, p. 419-468, 2017.

BROWN, A. What is so special about online (as compared to offline) hate speech?. Ethnicities, v. 18, n. 3, p. 297-326, 2018.

BRUGGER, W. Proibição ou proteção do discurso do ódio? Algumas observações sobre o direito alemão e o americano. Direito Público, v. 4, n. 15, 2007.

CITRON, D. K. Hate crimes in cyberspace. Harvard University Press, 2014.

CONSANI, C. F. Democracia e os discursos de ódio religioso: O debate entre Dworkin e Waldron sobre os limites da tolerância. ethic@-An international Journal for Moral Philosophy, v. 14, n. 2, p. 174-197, 2015.

CORTINA, A. Aporofobia, el rechazo al pobre. Un desafío para la democracia. Barcelona: Paidós, 2017.

DAVIS, J. L. How artifacts afford: The power and politics of everyday things. MIT Press, 2020.

FACEBOOK. Discurso de Ódio. Disponível em: <https://www.facebook.com/communitystandards/hate_speech Acessado em 01 de agosto de 2017>.

FROIO, C.; GANESH, B. The transnationalisation of far right discourse on Twitter: Issues and actors that cross borders in Western European democracies. European Societies, v. 21, n. 4, p. 513-539, 2019.

HELMOND, A. A Plataformização da Web. Métodos Digitais: teoria-prática-crítica, p. 49, 2019.

MENDONÇA, R. F.; AMARAL, E. F. L. Racionalidade online: provimento de razões em discussões virtuais. Opinião Publica, v. 22, p. 418-445, 2016.

MEZA, R. M.; VINCZE, H. O.; MOGOS, A. Targets of Online Hate Speech in Context. Intersections, v. 4, n. 4, 2018.

NEUENDORF, K. A. The content analysis guidebook. Thousand Oaks, CA: Sage Publications, 2002.

NOVAES, J. V. O intolerável peso da feiura: sobre as mulheres e seus corpos. Editora Garamond, 2006.

PERES, W. S. Juventudes, diversidade e processos de subjetivação. In: PESSINI, L.; ZACHARIAS, Z. (Ed), Ética teológica e juventudes: Interpelações recíprocas (pp.51-84). Aparecida: Editora Santuário. 2013.

PÉLLICO NETTO, S.; BRENA, D. A. Inventário florestal. Curitiba: Universidade Federal do Paraná, 1997. 316 p. 
RIEDER, B. Studying Facebook via data extraction: the Netvizz application. In: Proceedings of the 5th Annual ACM Web Science Conference (WebSci '13). New York, USA: Association for Computing Machinery, 2013, p. 346-355.

RIZZOTTO, C.; SARAIVA, A. Violência de gênero em debate: uma análise das conversações sobre a lei do feminicídio na fanpage do Senado Federal. InTexto, p. 249-269, 2020.

ROGERS, R. Otherwise Engaged: Social Media from Vanity Metrics to Critical Analytics. International Journal of Communication, v. 12, p. 23, 2018.

SAMPAIO, R.; LYCARIAO, D. Eu quero acreditar! Da importância, formas de uso e limites dos testes de confiabilidade na Análise de Conteúdo. Revista de Sociologia \& Política., v. 26, n. 66, p. 31-47, 2018.

SARMENTO, R. Sobre a cor de Machado e o corpo de Gisele: expressões políticas em espaços ordinários na internet. Temática, v. 4, p. 1-19, 2013.

SCHÄFER, G.; LEIVAS, P. G. C.; SANTOS, R. H. Discurso de ódio: da abordagem conceitual ao discurso parlamentar. Revista de Informação Legislativa-RIL. Brasília, v. 52, p. 143-158, 2015.

SILVA, L. R. L.; SAMPAIO, R. C. Impeachment, Facebook e discurso de ódio: a incivilidade e o desrespeito nas fanpages das senadoras da república. Esferas, v. 6, n. 10, 2017.

SILVA, U. B. Racismo e alienação: uma aproximação à base ontológica da temática racial. Instituto Lukács, 2012.

SPONHOLZ, L. O papel dos discursos de ódio (online) na ascensão da extrema direita: um aporte teórico. Confluências,v. 22, n. 3, p. 220-243, 2020.

TUNES, E. Preconceito, inclusão e deficiência - o preconceito no limiar da deficiência. Nos limites da ação: preconceito, inclusão e deficiência, p. 51-56, 2007.

VAN DIJCK, J.; POELL, T.; DE WAAL, M. The platform society: Public values in a connective world. Oxford University Press, 2018.

VEIGA DA SILVA, M. Masculino, o gênero do jornalismo: modos de produção das notícias. Florianópolis: Insular, 2014.

Artigo recebido em 08/12/2020 e aprovado em 16/03/2021. 